\title{
Effect of nitric oxide synthase on multiple drug resistance is related to Wnt signaling in non-small cell lung cancer
}

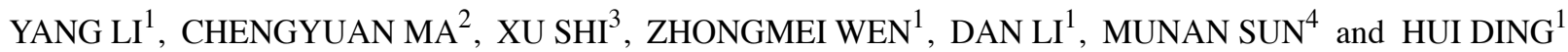 \\ Departments of ${ }^{1}$ Respiration and ${ }^{2}$ Neurosurgery, The First Hospital of Jilin University; ${ }^{3}$ Department of Central Laboratory \\ of the First Affiliated Hospital, and College of Basic Medical Sciences, Jilin University, Changchun, Jilin 130021; \\ ${ }^{4}$ Cancer Biotherapy Center, Jilin Province People's Hospital, Changchun, Jilin 130000, P.R. China
}

Received April 23, 2014; Accepted June 6, 2014

DOI: $10.3892 /$ or.2014.3351

\begin{abstract}
Multiple drug resistance (MDR) is considered a major challenge in the clinical treatment of non-small cell lung cancer (NSCLC). Both nitric oxide synthase (iNOS) and Wnt signaling pathway participate in the regulation of drug resistance, but the interaction between them remains unclear. In the present study, we detected the activation of $\mathrm{Wnt} / \beta$ catenin signaling in iNOS-induced drug-resistant lung cancer cells, and compared the effect of canonical and noncanonical Wnt pathway on the level of iNOS. Moreover, we investigated the expression of $\mathrm{Wnt} / \beta$-catenin signaling downstream factors and its main inhibitors. The results indicated iNOSinduced drug resistance was possibly mediated by glutathione S-transferase- $\pi$ (GST- $\pi$ ) and topoisomerase II $\alpha$ (TOPO II $\alpha$ ), but not P-glycoprotein (P-gp), and this process was closely associated with the activation of canonical Wnt/ $\beta$-catenin signaling, but less with noncanonical pathways. The mechanism of iNOS promoting Wnt/ $\beta$-catenin pathway was mainly dependent on the inverse regulation of Dickkopf-1 (DKK-1) and secreted frizzled-related protein-1 (SFRP-1). Clarifying the relationship between iNOS and Wnt signaling may provide insight into a better understanding of the mechanism of drug resistance development in NSCLC.
\end{abstract}

\section{Introduction}

Lung cancer is the leading cause of cancer-related mortality worldwide, accounting for $26 \%$ of all female and $28 \%$ of all male cancer deaths in 2013 (1). In China, the crude mortality rates in 2008 were 47.51 per 100,000 men and 22.69 per 100,000 women (2). Of all lung cancer occurrences, $\sim 85 \%$ are non-small cell lung cancer (NSCLC) (3), which is a lethal

Correspondence to: Professor Hui Ding, Department of Respiration, The First Hospital of Jilin University, Changchun, Jilin 130021, P.R. China

E-mail: dinghui08@163.com

Key words: nitric oxide synthase, Wnt, signaling transduction, drug resistance, non-small cell lung cancer malignancy with a 5-year survival rate of only $\sim 15 \%(4,5)$. Standard treatment for patients with NSCLC typically includes radiotherapy, platinum-based chemotherapy and non-platinum agent $(6,7)$. However, the prognosis of lung cancer remains poor, owing mainly to the acquired or inherent drug resistance of cancer cells.

Drug resistance is a highly common phenomenon in the clinical chemotherapy of leukemia or other solid tumors, and these cancer cells may also become cross-resistant to various chemotherapeutics, leading to multiple drug resistance (MDR). Previous research found several mechanisms for MDR, such as overexpression of transporter superfamily members, mutation or alteration in drug target genes, activation of mitogen-activated protein kinase (MAPK) cascade and phosphatidylinositol-3-kinase (PI3K)/Akt signaling pathway $(8,9)$.

Nitric oxide (NO) has been shown to play important roles in the innate immune response, neovascularization, cancer metastasis and cell death (10-12). Recently, long-term exposure to NO was found to render lung cancer cells resistant to cisplatin, doxorubicin and etoposide in a dose- and time-dependent manner by increasing the level of caveolin-1 (CAV-1), antiapoptotic B-cell lymphoma-2 (Bcl-2) and activated protein kinase B (AKT) (13). In the present study, MDR-related factors glutathione S-transferase- $\pi(\mathrm{GST}-\pi)$ and topoisomerase II $\alpha$ (TOPO II $\alpha$ ) but not P-glycoprotein (P-gp) were found to be regulated by induced nitric oxide synthase (iNOS) in A549/CDDP, and this process was directly mediated by the Wnt signaling pathway. Moreover, we found iNOS was mainly influenced by canonical Wnt/ $\beta$-catenin signaling but not noncanonical Wnt pathways. Furthermore, we detected the expression of $\mathrm{Wnt} / \beta$-catenin downstream factors and inhibitors. The results indicated blocking iNOS could inactivate Wnt/ $\beta$-catenin signaling, and this function might be mediated by Dickkopf-1 (DKK-1) and secreted frizzled-related protein-1 (SFRP-1). Our findings may help elucidate the relationship between iNOS and Wnt signaling in the process of drug resistance in NSCLC.

\section{Materials and methods}

Cell lines and reagents. The human cisplatin-tolerant NSCLC cell line A549/CDDP was obtained from the American Type 
Culture Collection (ATCC). Cells were cultured at $37^{\circ} \mathrm{C}$ in $5 \% \mathrm{CO}_{2}$ in Dulbecco's modified Eagle's medium (DMEM; Invitrogen), containing 10\% FBS (Clontech) and penicillin streptomycin solution (Hyclone). Human TNF- $\alpha$, IL-1 $\beta$ and IFN- $\gamma$ obtained from R\&D Systems were used to induce the production of NO as previously described (14). iNOS selective inhibitor S-methylisothiourea sulfate (SMT) was obtained from Beyotime (China). Recombinant human DKK-1 was from PeproTech, used to generally block Wnt pathways. XAV939 and SP600125 (both from Selleck) and Xec (Merck) were chosen to inhibit Wnt/ $\beta$-catenin, Wnt/JNK and Wnt/ $\mathrm{Ca}^{2+}$ pathways respectively. Protein levels were normalized to $\beta$-actin.

Analysis of $m R N A$ levels by RT-PCR. Total cellular RNA was isolated with TRIzol reagent (Invitrogen) and reverse transcribed into cDNA using Sprint RT complete products kit (Clontech). The gene-specific primers for RT-PCR are listed in Table I.

Western blot analysis. A549/CDDP cells were plated in 6-well plates $\left(3 \times 10^{6}\right.$ cells/well). Following inflammatory cytokine mixture stimulation for $4 \mathrm{~h}$, inhibitors of iNOS and Wnt pathways were added to the medium. After $8 \mathrm{~h}$ treatment of these antagonists, cells were harvested and homogenized with lysis buffer. Total protein was separated by denaturing $10 \%$ SDS-polyacrylamide gel electrophoresis. Detection was performed with Odyssey system (Gene). The primary antibodies for iNOS, P-gp, TOPO II $\alpha$, GST- $\pi$, Wnt-3a/5a/8a/11, Fzd-8, $\beta$-catenin, Axin, APC, phospho-GSK-3 $\beta$ (Ser9), GSK3 $\beta$, Wif-1, DKK-1, SFRP-1 and $\beta$-actin were all obtained from Santa Cruz Biotechnology. The animal-matched horseradish peroxidase-conjugated secondary antibody was purchased from Santa Cruz Biotechnology.

ELISA. NO is rapidly oxidized to nitrite and nitrate which are used to quantitate NO production. BioVision's Nitric Oxide Colorimetric Assay Kit provided an accurate, convenient measure of total nitrate/nitrite in a simple two-step process. The amount of the azo chromophore accurately reflected NO amount in samples.

Statistical analysis. Data are presented as the mean \pm SD. Experiments were carried out in duplicate or triplicate, and were all conducted a minimum of three times. Data were analyzed by the Student's t-test or ANOVA where appropriate. $\mathrm{P}<0.05$ was considered to indicate a statistically significant difference.

\section{Results}

Inhibition of Wht signaling decreases the NO-induced drug resistance in A549/CDDP. In inflammation conditions, the iNOS gene is often activated, resulting in the production of NO. Thus, the pro-inflammatory cytokines TNF- $\alpha$, IL-1 $\beta$ and IFN $-\gamma$ were used to trigger the expression of iNOS in our experiment (14-17). To investigate the Wnt signaling pathway, DKK-1 was added into the medium to inhibit the Wnt pathway. The expressions of P-gp, TOPO II $\alpha$ and GST- $\pi$ were chosen to reflect the extent of the drug resistance, and the level of NO in the culture media was evaluated by ELISA.
Table I. Primer sequences used in RT-PCR.

\begin{tabular}{|c|c|}
\hline Gene & Primer \\
\hline iNOS & $\begin{array}{l}\text { F: 5'-ACAAGCTGGCCTCGC TCTGGAAAGA-3' } \\
\text { R: 5'-TCCATGCAGACAACCTTGGGGTTGAAG-3 }\end{array}$ \\
\hline P-gp & $\begin{array}{l}\text { F: 5'-ACTTCCACATCTGCTTCGTCAGTG-3' } \\
\text { R: 5'-ATTCAGCCACAGGAGGTAGAGAGC-3' }\end{array}$ \\
\hline GST- $\pi$ & $\begin{array}{l}\text { F: 5'-TGGGCATCTGAAGCCTTTTG-3' } \\
\text { R: 5'-GATCTGGTCACCCACGATGAA-3' }\end{array}$ \\
\hline TOPO II $\alpha$ & $\begin{array}{l}\text { F: 5'-AAGGTTTGGGCACCAGCAC-3' } \\
\text { R: 5'-CTCGCTTGTCATTCCGTTTG-3' }\end{array}$ \\
\hline Wnt-3a & $\begin{array}{l}\text { F: 5'-TCCACGCCATTGCCTCAG-3' } \\
\text { R: 5'-GACCACCAGCATGTCTTCACC-3' }\end{array}$ \\
\hline Wnt-5a & $\begin{array}{l}\text { F: 5'-ACAACCTGGCTGATGTGGC-3' } \\
\text { R: 5'-CGTCTGCACGGTCTTGAACT-3' }\end{array}$ \\
\hline Wnt-8a & $\begin{array}{l}\text { F: 5'-CCTATCTGACCTACACGACTAGTGT-3' } \\
\text { R: 5'-CGTTCCCAAGCAAACTGG-3' }\end{array}$ \\
\hline Wnt-11 & $\begin{array}{l}\text { F: 5'-AAGGACTCGGAACTCGTCTATC-3' } \\
\text { R: 5'-GCAGCACCAGTGGTACTTACAG-3' }\end{array}$ \\
\hline Wif-1 & $\begin{array}{l}\text { F: 5'-ACCTGGATTCTATGGAGTGAACTGT-3' } \\
\text { R: 5'-GTATGAGGCTGGCTTCGTACCT-3' }\end{array}$ \\
\hline SFRP-1 & $\begin{array}{l}\text { F: 5'-GCTTCCAGTCGGACATCG-3' } \\
\text { R: 5'-AGCATCTCGGGCCAGTAG-3' }\end{array}$ \\
\hline DKK-1 & $\begin{array}{l}\text { F: 5'-TTCCAACGCTATCAAGAACCT-3' } \\
\text { R: 5'-CCAAGGTGCTATGATCATTACC-3' }\end{array}$ \\
\hline$\beta$-actin & $\begin{array}{l}\text { F: 5'-ATGGATGATGATATCGCCGCGCT-3' } \\
\text { R: 5'-GACTCGATGCCCAGGAAGGA-3' }\end{array}$ \\
\hline
\end{tabular}

F, forward; R, reverse.

Following stimulation with the TNF- $\alpha /$ IL-1 $\beta /$ IFN- $\gamma$ combination, the expression of GST- $\pi$ was clearly upregulated, while that of TOPO II $\alpha$ decreased. Although P-gp was also reduced after Wnt pathway blocking, its expression was not significantly altered (Fig. 1A and B). An increasing concentration of $\mathrm{NO}$ in the culture media was observed, as shown in Fig. 1C, demonstrating the activation of iNOS. The results indicated that the resistance of A549/CDDP to cisplatin was positively increased by high level of iNOS, and DKK-1 reversed the drug resistance mainly by regulating GST- $\pi$ and TOPO II $\alpha$.

The level of $i N O S$ is positively correlated with the canonical but not the noncanonical Wnt/ $\beta$-catenin signaling. Although the effect of Wnt signaling in iNOS-induced drug resistance was confirmed in our experiment, the differences between canonical and noncanonical Wnt pathways in regulating the level of iNOS were still unclear. By treatment with Wnt/ $\beta$-catenin inhibitor XAV939 $(18,19), \mathrm{Wnt} / \mathrm{Ca}^{2+}$ inhibitor XeC $(20,21)$ and Wnt/JNK inhibitor SP600125 respectively in A549/CDDP, we found a lower iNOS and GST- $\pi$, and a higher TOPO II $\alpha$ in the Wnt/ $\beta$-catenin-blocking group. However, neither Wnt/JNK nor Wnt/Ca ${ }^{2+}$ pathway were correlated with iNOS, GST- $\pi$ and 
$\mathbf{A}_{\text {In }}$
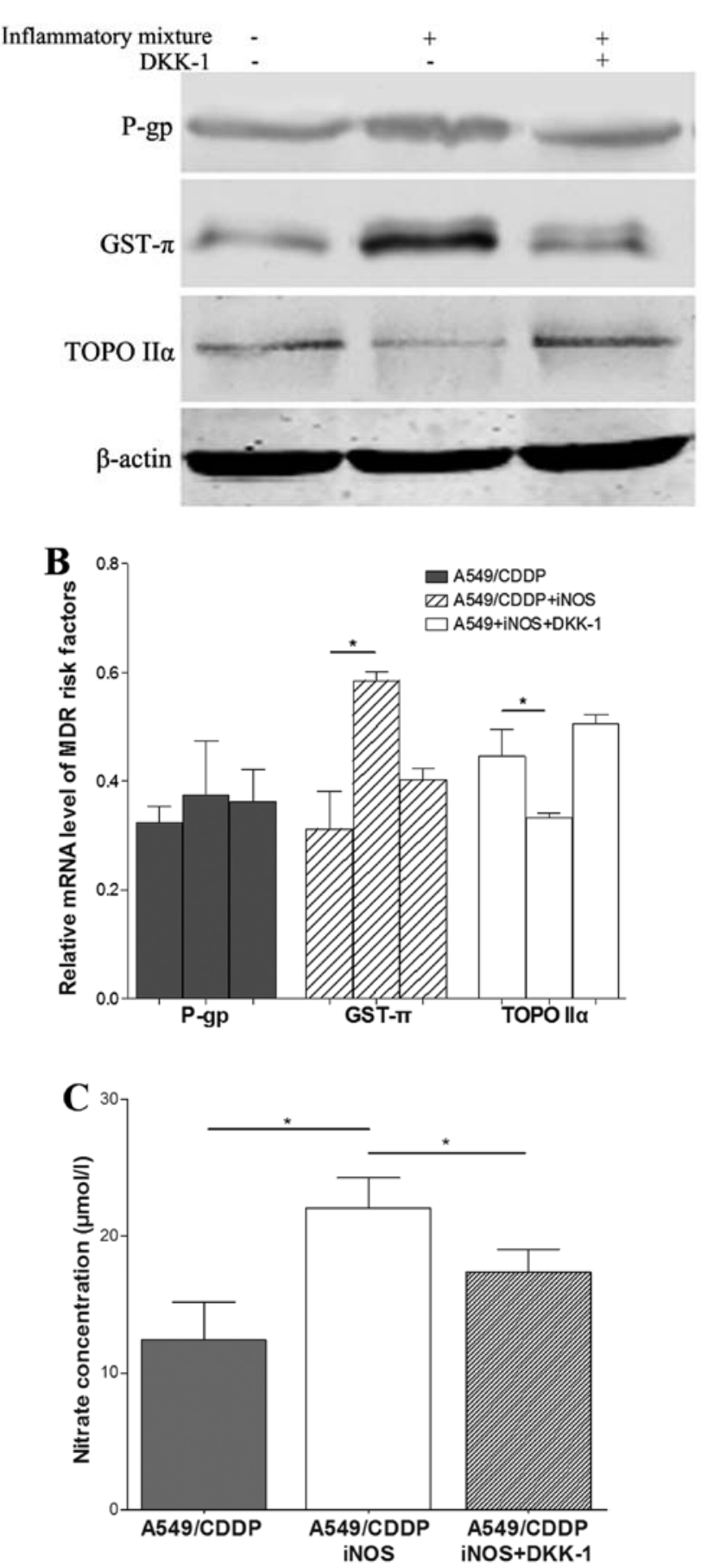

Figure 1. The effect of Wnt signaling on NO-induced drug resistance. (A) A549/CDDP cells were treated with inflammatory mixture containing $1,000 \mathrm{U} / \mathrm{ml} \mathrm{TNF}-\alpha, 100 \mathrm{U} / \mathrm{ml} \mathrm{IL}-1 \beta$, and $250 \mathrm{U} / \mathrm{ml} \mathrm{IFN-} \gamma$ for $4 \mathrm{~h}$, and $100 \mathrm{ng} / \mathrm{ml}$ DKK-1 was added to the medium for $8 \mathrm{~h}$ to investigate the level of drug-resistant related factors. (B) Corresponding mRNA levels of GST- $\pi$, TOPO II $\alpha$ and P-gp. (C) The change of nitrate concentration, which was induced by TNF- $\alpha / \mathrm{IL}-1 \beta / \mathrm{IFN}-\gamma,{ }^{*} \mathrm{P}<0.05$.

TOPO II $\alpha$ as shown in Fig. 2A. P-gp was clearly downregulated in noncanonical Wnt pathways, and that might be related to other signals influenced by XeC and SP600125.

Furthermore, we detected the effect of iNOS on canonical and noncanonical Wnt signaling represented secretions (Wnt-3a/Wnt-8a and Wnt-5a/Wnt-11, respectively) (22-24). Consistent with our previous results, inhibition of iNOS led
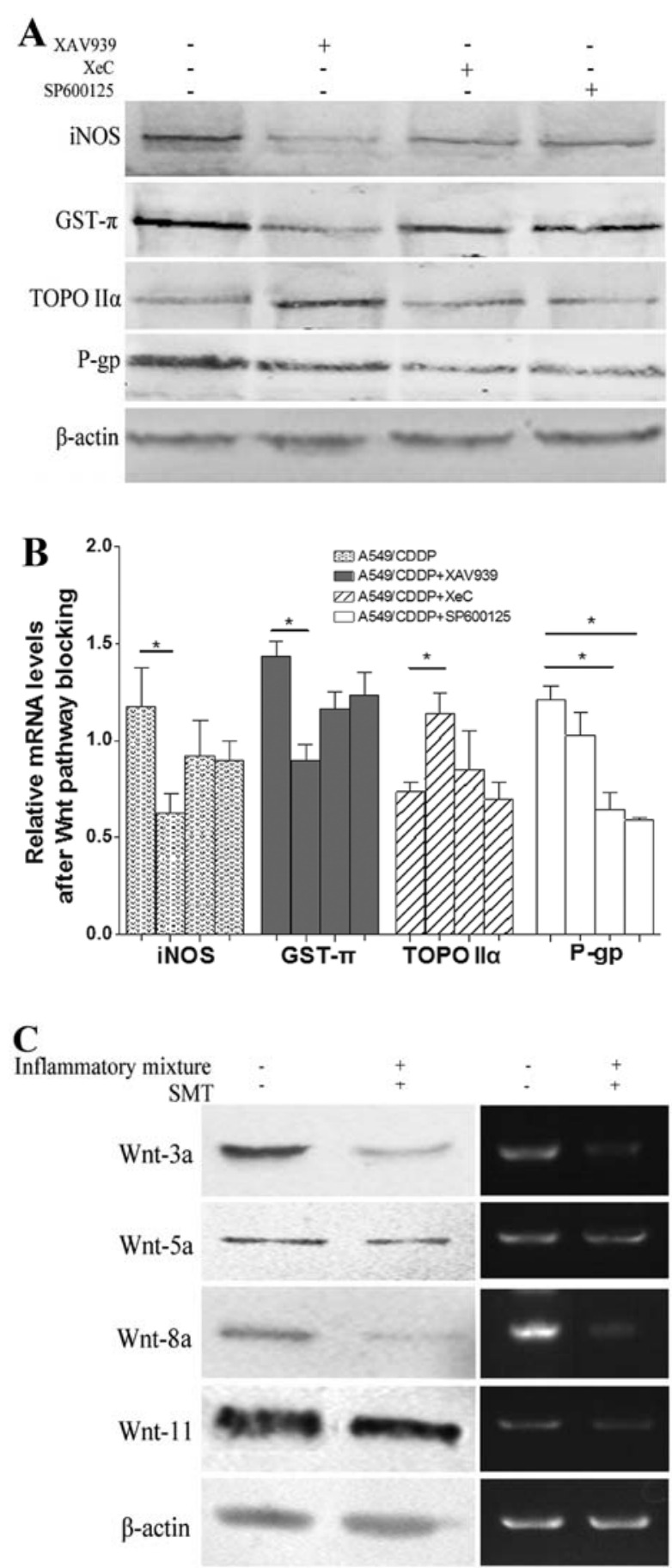

Figure 2. The relationship between iNOS and canonical/noncanonical Wnt pathways. (A) The change of iNOS and drug-resistant factors after treatment with Wnt/ $\beta$-catenin inhibitor XAV939 $(1 \mu \mathrm{mol} / \mathrm{l}), \mathrm{Wnt} / \mathrm{Ca}^{2+}$ inhibitor XeC $(2 \mu \mathrm{mol} / 1)$ and Wnt/JNK inhibitor SP600125 $(10 \mu \mathrm{mol} / \mathrm{l})$. (B) Corresponding mRNA levels of iNOS, GST- $\pi$, TOPO II $\alpha$ and P-gp, ${ }^{*} \mathrm{P}<0.05$. (C) The effect of iNOS on canonical Wnt-3a/Wnt-8a and noncanonical Wnt-5a/Wnt-11.

to an obviously decreased expression of Wnt-3a and Wnt-8a which indicated canonical Wnt signaling, but noncanonical Wnt-5a and Wnt-11 were not significantly influenced by iNOS, as shown in Fig. 2B.

Inhibition of iNOS is positively associated with the Wnt/ $\beta$-catenin signaling pathway and its downstream factors. 


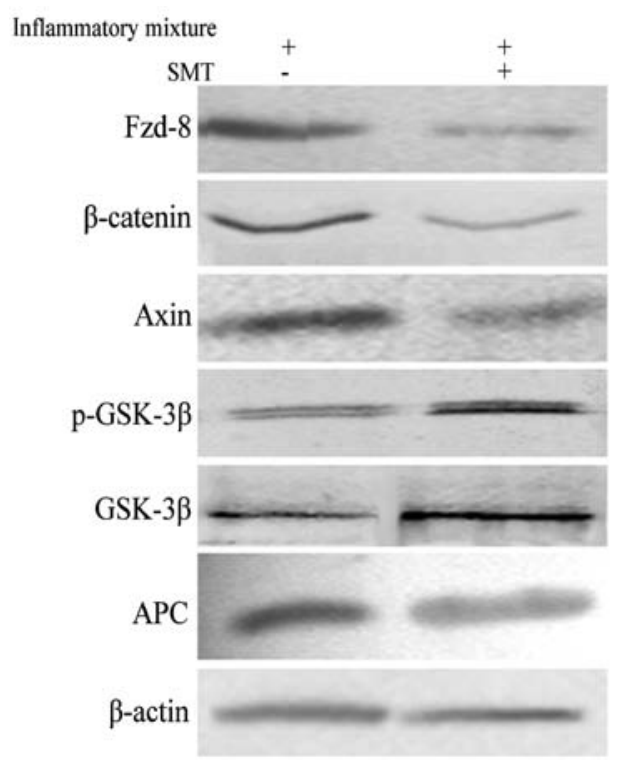

Figure 3. The effect of iNOS on Wnt/ $\beta$-catenin downstream factors. By preventing the expression of iNOS by its highly selective inhibitor SMT $(1 \mathrm{mmol} / \mathrm{l})$ in A549/CDDP, a lower Fzd-8, $\beta$-catenin and Axin, and a higher p-GSK-3 $\beta$ and GSK-3 $\beta$ were observed. The expression of APC had no statistical significance after iNOS blocking.

The signaling transduction of canonical Wnt/ $\beta$-catenin pathway has been well described. Following binding of Wnt to its receptor frizzled (FZD) and lipoprotein receptor-related protein 5/6 (LRP5/6), dishevelled proteins (DSH) become activated, leading to the inactivation of the Axin/adenomatous polyposis coli (APC)/glycogen synthase kinase (GSK) $3 \beta$ complex which mediated $\beta$-catenin degradation, and resulting in the accumulation of $\beta$-catenin. Then, the $\beta$-catenin proteins translocated to the nucleus and interacted with transcription factors of the T cell factor (TCF) and lymphoid-enhancing factor (LEF) families, promoting the transcription of many oncogenic factors, such as c-Myc, cyclin D1 and VEGF (25-29). By preventing the expression of iNOS by its highly selective inhibitor SMT in A549/CDDP, we observed a decreasing level of Fzd- $8, \beta$-catenin and Axin, and an increased p-GSK-3 $\beta$ and GSK-3 $\beta$-expression. However, the change in APC showed no statistical significance compared with that in no-SMT control as shown in Fig. 3.

The level of DKK-1 and SFRP-1 inversely regulate the $i N O S$ and Wnt/ $\beta$-catenin signaling. As a core modulator, Wnt/ $\beta$-catenin transduction pathway was regulated by a precise mechanism, containing positive and negative feedback. The general opposite control has been considered to be mediated by Wnt antagonists such as endogenic DKK-1, SFRP-1 and Wif-1. The main inhibitory mechanism is the interference of the combination between Wnt and its receptors (14,30-33). Fig. 4 shows the influence of iNOS on Wif-1, DKK-1 and SFRP-1. In accordance with a previous study, the results indicated DKK-1 was increased after iNOS blocking (14). In addition, the expression of SFRP-1 also showed a negative correlation with iNOS level, but Wif-1 appeared to be less associated with this factor. Thus, we concluded that iNOS could increase drug resistance in NSCLC by inhibiting DKK-1 and SFRP-1.

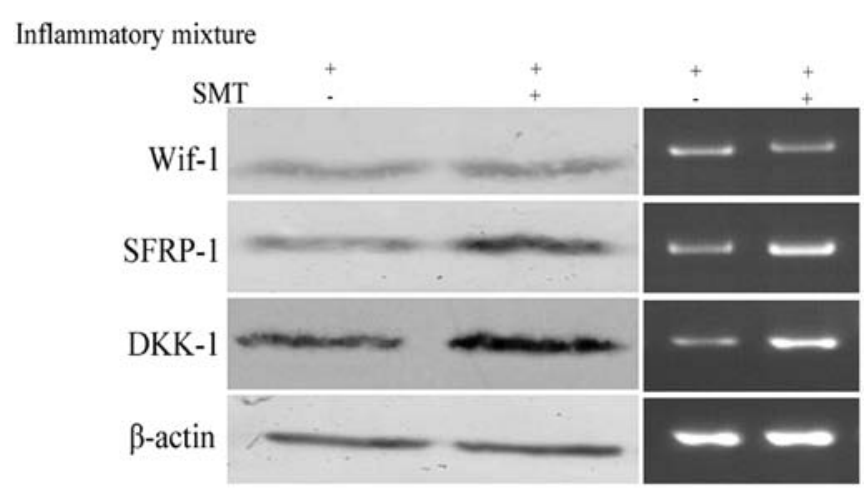

Figure 4. The influence of iNOS on Wnt antagonists. By blocking iNOS, endogenic Wnt inhibitors Wif-1, DKK-1 and SFRP-1 were increased but Wif-1 seemed to be less influenced by iNOS. Thus, the positive regulation of iNOS to Wnt signaling was mainly by decreasing DKK-1 and SFRP-1.

\section{Discussion}

Extensive studies have been performed to elucidate the mechanism underlying multiple drug resistance (MDR) in non-small cell lung cancer (NSCLC) in the past ten years. One of the important components of the tumor microenvironment, nitric oxide (NO), has been found to be markedly increased in drug-resistant NSCLC. As a reactive nitrogen species, NO is catalytically synthesized by iNOS, promoting tumor formation, metastasis and differentiation through P53, NF- $\mathrm{KB}$, EGFR and other transduction pathways, including Wnt signaling, which is also considered a core pathway highly activated in drug-resistant lung cancer cells. Previous studies have shown the human iNOS gene is a transcriptional target of Wnt signaling, while iNOS-overexpression increased the levels of downstream effectors of the Wnt pathway such as c-Myc and cyclin D1 (14,34-36).

In this study, we focused on the relationship between iNOS and Wnt signaling in cisplatin-resistant lung cells A549/CDDP. By inhibiting the Wnt pathway by DKK-1, the iNOS-induced drug resistance was confirmed to be reversed. Furthermore, we found Wnt signaling could influence TOPO II $\alpha$ and GST- $\pi$, but affected P-gp less directly. As is known, P-gprelated resistance mainly acts against natural and lipophilic anti-cancer drugs $(37,38)$, thus it may not play a key role in this non-lipophilic drug-induced cell line, leading to a slight change of P-gp levels.

To further differentiate among three Wnt signaling pathways in the regulation of iNOS, we chose XAV939, XeC and SP600125 to inhibit Wnt/ $\beta$-catenin, Wnt/ $\mathrm{Ca}^{2+}$ and $\mathrm{Wnt} / \mathrm{JNK}$ pathways respectively. The results clearly demonstrated higher TOPO II $\alpha$ and lower iNOS/GST- $\pi$ levels in the XAV939 treatment group compared with that in the other two inhibitor groups. The expression of P-gp was only slightly altered in the XAV939 group, but it was downregulated in the $\mathrm{XeC}$ and SP600125 groups. That is possibly because SP600125 and $\mathrm{XeC}$ could disturb other core signal transductions related to P-gp-expression, except the inhibition of JNK1/2 and $\mathrm{Ca}^{2+}$.

To confirm the effect of iNOS on canonical and noncanonical Wnt signaling, we also investigated the corresponding secretions, Wnt-3a/Wnt-8a and Wnt-5a/Wnt-11, respectively. 
Consistent with what we observed, inhibition of iNOS led to an obviously decreased Wnt-3a and Wnt-8a level, which indicated canonical Wnt signaling, but noncanonical Wnt-5a and Wnt-11 levels were less altered. The results indicated the iNOS-induced drug resistance was mainly mediated by canonical Wnt/ $\beta$-catenin signaling, but not by the other two noncanonical pathways.

After establishing the relationship between iNOS and Wnt/ $\beta$-catenin signaling in A549/CDDP, we detected the effect of iNOS on downstream factors of this pathway, containing membrane co-receptor Fzd, and $\beta$-catenin/APC/GSK-3 $\beta / A x i n$ compound. In humans, there are $10 \mathrm{Fzd}$ genes which may be divided into five subgroups: Fzd-1/2/7, Fzd-3/6, Fzd-5/8, Fzd-9/10 and Fzd-4 (39). Among them, Fzd-8 was confirmed to form a complex with Wnt $3 \alpha$ in vitro $(40,41)$. Thus, we tested the expression of Fzd- $8, \beta$-catenin, APC and Axin, and the phosphorylation of GSK-3 $\beta$ was assessed as well. By blocking iNOS by SMT, we observed a decreasing level of Fzd-8, $\beta$-catenin and Axin, a higher p-GSK-3 $\beta$ and GSK-3 $\beta$ expression, but a slight change of APC. Thus the effect of iNOS on the Wnt/ $\beta$-catenin pathway was mainly mediated by Fzd- 8 and p-GSK-3 $\beta$. It is of note that Axin, as a negative modulator in the canonical Wnt pathway, was downregulated after iNOS inhibition, and we speculated it might be because Axin has multi functions influenced by iNOS in tumor proliferation or other processes.

To explain the mechanism of iNOS-induced positive regulation on Wnt/ $\beta$-catenin signaling, we further investigated three widely accepted antagonists of this pathway, Wif-1, DKK-1 and SFRP-1. Human Wif-1 protein contains a Wnt inhibitory factor (Wif) domain, can bind to seven Wnts (3a, 4, 5a, 7a, 8, 9a and 11) (42,43), directly competing with Wnt for binding to its membrane receptors. DKK-1 works by inhibiting Wnt co-receptors LRP5/6 through binding cell surface Kremen-1 or Kremen- 2 and thus promoting the internalization of LRP5/6. As a type of secreted frizzled-related protein, SFRP can suppress the transduction of Wnt pathway signaling by competitively binding with Fzd receptor. Consistent with other reports that DKK1 expression is inversely correlated with iNOS and $\beta$-catenin translocation, we also observed the negative correlation between DKK-1 and iNOS. Furthermore, SFRP-1 was indicated to be inversely regulated by iNOS as well, but Wif-1 seemed to be less associated with this factor. In the present study, we presumed that there exists a balance between Fzd and its relative secreted protein SFRP, and blocking iNOS might promote the balance switches from Fzd to SFRP, inducing Wnt/ $\beta$-catenin pathway inactivation, and finally increasing the sensitivity of A549/CDDP cells to cisplatin.

The relationship between iNOS and Wnt signaling has attracted considerable attention for its multiple functions in tumor; hence, clarifying the detailed mechanism of its regulation may help to better understand the mechanism of drug resistance, and may aid in the development of new targets for reversing drug resistance in NSCLC.

\section{Acknowledgements}

This study was supported by The Fourth Youth Foundation of the First Hospital of Jilin University (JDYY42013008).

\section{References}

1. Keith RL and Miller YE: Lung cancer chemoprevention: current status and future prospects. Nat Rev Clin Oncol 10: 334-343, 2013.

2. She J, Yang P, Hong Q and Bai C: Lung cancer in China: challenges and interventions. Chest 143: 1117-1126, 2013.

3. Yang Y, Li H, Hou S, Hu B, Liu J and Wang J: The noncoding RNA expression profile and the effect of lncRNA AK126698 on cisplatin resistance in non-small-cell lung cancer cell. PLoS One 8: e65309, 2013.

4. Grutters JPC, Kessels AGH, Pijls-Johannesma M, de Ruysscher D, Joore MA and Lambin P: Comparison of the effectiveness of radiotherapy with photons, protons and carbon-ions for non-small cell lung cancer: a meta-analysis. Radiother Oncol 95: 32-40, 2010.

5. Herbst R, Heymach J and Lippman S: Molecular origins of cancer. N Engl J Med 359: 1367-1380, 2008.

6. Schiller JH, Harrington D, Belani CP, et al: Comparison of four chemotherapy regimens for advanced non-small-cell lung cancer. N Engl J Med 346: 92-98, 2002.

7. Scagliotti GV, Parikh P, von Pawel J, et al: Phase III study comparing cisplatin plus gemcitabine with cisplatin plus pemetrexed in chemotherapy-naive patients with advanced-stage non-small-cell lung cancer. J Clin Oncol 26: 3543-3551, 2008.

8. Mackay HJ, Twelves CJ: Protein kinase C: a target for anticancer drugs? Endocr Relat Cancer 10: 389-396, 2003.

9. Hiss D: Optimizing molecular-targeted therapies in ovarian cancer: the renewed surge of interest in ovarian cancer biomarkers and cell signaling pathways. J Oncol 2012: 737981, 2012.

10. Jenkins DC, Charles IG, Thomsen LL, et al: Roles of nitric oxide in tumor growth. Proc Natl Acad Sci USA 92: 4392-4396, 1995.

11. Xu WM, Liu LZ, Loizidou M, Ahmed M and Charles IG: The role of nitric oxide in cancer. Cell Res 12: 311-320, 2002.

12. Chen GG, Lee TW, Xu H, Yip JH, Li M, Mok TS and Yim AP: Increased inducible nitric oxide synthase in lung carcinoma of smokers. Cancer 112: 372-381, 2008.

13. Wongvaranon P, Pongrakhananon V, Chunhacha $\mathrm{P}$ and Chanvorachote P: Acquired resistance to chemotherapy in lung cancer cells mediated by prolonged nitric oxide exposure. Anticancer Res 33: 5433-5444, 2013.

14. Du Q, Zhang X, Liu Q, Zhang X, Bartels CE and Geller DA: Nitric oxide production upregulates Wnt/ $\beta$-catenin signaling by inhibiting Dickkopf-1. Cancer Res 73: 6526-6537, 2013.

15. Vane JR, Mitchell JA, Appleton I, et al: Inducible isoforms of cyclooxygenase and nitric-oxide synthase in inflammation. Proc Natl Acad Sci USA 91: 2046-2050, 1994.

16. Nathan $\mathrm{C}$ and Xie QW: Nitric oxide synthases: roles, tolls, and controls. Cell 78: 915-918, 1994.

17. Gonzalez D, Rojas A, Herrera MB and Conlan RS: iNOS activation regulates $\beta$-catenin association with its partners in endothelial cells. PLoS One 7: e52964, 2012.

18. Sumi T, Oki S, Kitajima K and Meno C: Epiblast ground state is controlled by canonical Wnt/ $\beta$-catenin signaling in the postimplantation mouse embryo and epiblast stem cells. PLoS One 8: e63378, 2013.

19. Tian XH, Hou WJ, Fang Y, et al: XAV939, a tankyrase 1 inhibitor, promotes cell apoptosis in neuroblastoma cell lines by inhibitingWnt $/ \beta$-catenin signaling pathway. J Exp Clin Cancer Res 32: 100, 2013.

20. Gafni J, Munsch JA, Lam TH, et al: Xestospongins: potent membrane permeable blockers of the inositol 1,4,5-trisphosphate receptor. Neuron 19: 723-733, 1997.

21. Westfall TA, Brimeyer R, Twedt J, et al: Wnt-5/pipetail functions in vertebrate axis formation as a negative regulator of Wnt/beta-catenin activity. J Cell Biol 162: 889-898, 2003.

22. Cadigan KM and Nusse R: Wnt signaling: a common theme in animal development. Genes Dev 11: 3286-3305, 1997.

23. Logan CY and Nusse R: The Wnt signaling pathway in development and disease. Annu Rev Cell Dev Biol 20: 781-810, 2004.

24. Moon RT, Brown JD and Torres M: WNTs modulate cell fate and behavior during vertebrate development. Trends Genet 13: 157-162, 1997.

25. Nakajima M, Fukuchi M, Miyazaki T, Masuda N, Kato H and Kuwano H: Reduced expression of Axin correlates with tumour progression of oesophageal squamous cell carcinoma. Br J Cancer 88: 1734-1739, 2003.

26. Bryja V, Andersson ER, Schambony A, et al: The extracellular domain of $\mathrm{Lrp5} / 6$ inhibits noncanonical Wnt signaling in vivo. Mol Biol Cell 20: 924-936, 2009. 
27. Andersson ER, Bryjova L, Biris K, Yamaguchi TP, Arenas E and Bryja V: Genetic interaction between Lrp6 and Wnt5a during mouse development. Dev Dyn 239: 237-245, 2010.

28. Gao C, Chen YG: Dishevelled: The hub of Wnt signaling. Cell Signal 22: 717-727, 2010.

29. Mikels AJ and Nusse R: Purified Wnt5a protein activates or inhibits beta-catenin-TCF signaling depending on receptor context. PLoS Biol 4: 570-582, 2006.

30. Surana R, Sikka S, Cai W, Dharmarajan AM, Kumar AP et al: Secreted frizzled related proteins: implications in cancers. Biochim Biophys Acta 1845: 53-65, 2014.

31. Zhang J, Zhou B, Liu Y, et al: Wnt inhibitory factor-1 functions as a tumor suppressor through modulating Wnt $/ \beta$ catenin signaling in neuroblastoma. Cancer Lett 348: 12-19, 2014.

32. Kawano Y and Kypta R: Secreted antagonists of the Wnt signalling pathway. J Cell Sci 116: 2627-2634, 2003.

33. Bafico A, Liu G, Yaniv A, Gazit A and Aaronson SA: Novel mechanism of Wnt signalling inhibition mediated by Dickkopf-1 interaction with LRP6/Arrow. Nat Cell Biol 3: 683-686, 2001.

34. Du Q, Park KS, Guo Z, et al: Regulation of human nitric oxide synthase 2 expression by Wnt beta-catenin signaling. Cancer Res 66: 7024-7031, 2006.

35. Du Q, Zhang X, Cardinal J, et al: Wnt/beta-catenin signaling regulates cytokine-induced human inducible nitric oxide synthase expression by inhibiting nuclear factor-kappaB activation in cancer cells. Cancer Res 69: 3764-3771, 2009.
36. Du Q and Geller DA: Cross-regulation between Wnt and NF- $\kappa$ B signaling pathways. For Immunopathol Dis Therap 1: 155-181, 2010.

37. Pakos EE and Ioannidis JP: The association of P-glycoprotein with response to chemotherapy and clinical outcome in patients with osteosarcoma. A meta-analysis. Cancer 8: 581-589, 2003.

38. Geng G, Wang L, Chen X, Cao R and Li P: The association between chemosensitivity and Pgp, GST- $\pi$ and Topo II expression in gastric cancer. Diagn Pathol 8: 198, 2013.

39. MacDonald BT and He X: Frizzled and LRP5/6 receptors for Wnt $/ \beta$-catenin signaling. Cold Spring Harb Perspect Biol 4: a007880, 2012.

40. Bourhis E, Tam C, Franke Y, et al: Reconstitution of a Frizzled8-Wnt3a-LRP6 signaling complex reveals multiple Wnt and Dkk1 binding sites on LRP6. J Biol Chem 285: 9172-9179, 2010.

41. Tamai K, Semenov M, Kato Y, et al: LDL-receptor-related proteins in Wnt signal transduction. Nature 407: 530-535, 2000.

42. Hsieh JC, Kodjabachian L, Rebbert ML, et al: A new secreted protein that binds to Wnt proteins and inhibits their activities. Nature 398: 431-436, 1999.

43. Surmann-Schmitt C, Widmann N, Dietz U, et al: Wif-1 is expressed at cartilage-mesenchyme interfaces and impedes Wnt3a-mediated inhibition of chondrogenesis. J Cell Sci 122: 3627-3637, 2009. 